Version of Record: https://www.sciencedirect.com/science/article/pii/S0755498219300442

Manuscript_0ec692fbf641d216518293c7606b4be5

LA SANTE BUCCO-DENTAIRE DES PATIENTS SCHIZOPHRENES : UNE ETUDE FRANÇAISE TRANSVERSALE MULTICENTRIQUE

\title{
ORAL HEALTH IN SCHIZOPHRENIA PATIENTS: A FRENCH MULTICENTER
}

\section{CROSS-SECTIONAL STUDY}

Frederic Denis ${ }^{1,2,3}$, Gérard Milleret ${ }^{1}$, Thomas Wallenhorst ${ }^{4}$, Maud Carpentier ${ }^{5}$, Nathalie Rude $^{2}$, Benoit Trojak 6

${ }^{1}$ Clinical Research Unit, La Chartreuse Psychiatric Centre, 21033 Dijon, France.

${ }^{2}$ EA 481 Integrative Neurosciences and Clinical, University Hospital of Besançon, F-25000 Besançon, France

${ }^{3}$ Université Champagne Ardenne. Faculté d'odontologie de Reims, Département de santé publique, 2 rue du Général Koenig 51100 Reims, France

${ }^{4}$ Department of Psychiatry, Robert Morlevat Hospital Center, 21140 Semur-en-Auxois, France

${ }^{5}$ Direction de la Recherche Clinique, University Hospital of Dijon, 21079 Dijon Cedex, France

${ }^{6}$ Department of Psychiatry and Addictology, University Hospital of Dijon, 21079 Dijon, France

\section{Telephone number and email address of all authors}

Corresponding author: Frederic DENIS

La Chartreuse Psychiatric Center, Dijon, France

1, boulevard Chanoine Kir, BP 23314, 21033 Dijon Cedex, France

Tel.: +33 3804252 35, Email: frederic.denis@ chlcdijon.fr

\section{Acknowledgements}

The authors thank the staff and patients of all the hospitals (La Chartreuse Psychiatric Centre, University Hospital of Dijon and Semur en Auxois Hospitals) who participated in the survey. We thank Nicolas Abello, Sandrine Lombion and Valérie Bertaud for their assistance in writing the manuscript and Philip Bastable for his help with English language correction. We are grateful to the Regional Health Agency of Burgundy (Agence Régionale de Santé de Bourgogne) and the University Hospital of Dijon for the financial support given to the study. 


\section{Funding source}

This research project was funded by the Agence Régionale de Santé de Bourgogne (ARS).

Oral health in schizophrenia patients: a French multicenter cross-sectional study

Objective: The aim of this study was to assess the oral health status of a sample of patients with schizophrenia (PWS) in Côte d'Or region (France) and to determine the factors associated with dental status.

Material and Methods: A multicenter cross-sectional descriptive study was performed. PWS were selected using a random stratified method. Dental status was investigated using the Decayed, Missing, or Filled Teeth (DMFT) index, based on 32 teeth. The Simplified Oral Hygiene Index (OHI-S), the Xerostomia Index (XI) and the Global Oral Health Assessment Index (GOHAI) for Oral Health related Quality of Life (OHrQoL) were recorded.

Results: Among the 302 persons identified, 109 were included (acceptance rate was $49.1 \%$ ). Of these, $61.5 \%$ were men. The mean age was 46.8 years \pm 12.0 years. The majority (78\%) had completed a secondary education (SE). The mean duration of mental illness (DMI) was $17.9 \pm 9.4$ years, and $55.5 \%$ were taking drugs.

The mean DMFT was 16.6 \pm 8.1 . There was a significant relationship between age, SE, oral health variables, medical conditions and OHrQoL.

Conclusions: PWS describe a poor OHrQoL. The dental and hygiene index scores are poor. We observed a lack of brushing and of dental visit for these persons and a gap in oral health between PWS and general population.

\section{La santé bucco-dentaire des patients schizophrènes: une étude française transversale multicentrique}

Objectif : Le but de cette étude était d'évaluer l'état de santé bucco-dentaire d'un échantillon de patients atteints de schizophrénie (PS) en Côte d'Or (France) et de préciser les facteurs associés à la santé bucco-dentaire.

Matériel et méthodes : Une étude descriptive transversale multicentrique a été réalisée. Les PS ont été sélectionnés en utilisant une méthode stratifiée aléatoire. L'état de santé bucco- 
dentaire a été étudié en utilisant l'indice carieux (CAO) qui fait la somme des dents cariées, $(\mathrm{C})$, absentes $(\mathrm{O})$ et obturées $(\mathrm{O})$ basé sur 32 dents, l'indice d'hygiène buccale simplifié (OHIS), l'indice de xérostomie (XI) et un indice global d'évaluation de la qualité de vie lié à la santé bucco-dentaire, le Global Oral Health Assessment Index (GOHAI).

Résultats : Parmi les 302 personnes identifiées pour cette étude, 109 ont été incluses (taux d'acceptation de 49,1\%). Parmi celles-ci, 61,5\% étaient des hommes. L'âge moyen était de 46,8 ans $\pm 12,0$ ans. La majorité des PS (78\%) avaient terminé leurs études secondaires (ES). La durée moyenne de la maladie mentale était de 17,9 \pm 9,4 ans et 55,5\% prenaient des médicaments.

Le CAO moyen était de $16,6 \pm 8,1$. Il y avait une association significative l'âge, les ES, les variables de santé bucco-dentaire, les conditions médicales et la qualité de vie liée à la santé bucco-dentaire.

Conclusions : Les PS ont une mauvaise qualité de vie liée à leur santé bucco-dentaire. Les scores de l'indice dentaire et d'hygiène sont de mauvaises qualités. Nous avons observé un manque d'hygiène bucco-dentaire et de fréquentation des dentistes par ces populations ainsi qu'un écart entre la santé bucco-dentaire des PS et la population générale. 
Schizophrenia is a severe mental disorder that affects between $0.7 \%$ and $1 \%$ of the world's population, including 600,000 people in France [1]. Patients with schizophrenia (PWS) have high mortality (their life expectancy is reduced by 20\%) and morbidity [2]. Among physical comorbidities in PWS, poor oral health contributes to the overall poor health of these patients [3]. At various degrees of intensity, the symptoms of schizophrenia lead to disturbances in the progression of thought, errors in contextual analysis and errors of logic. PWS often do not recognize their health needs and delay seeking advice or treatment [4].

This issue occurs in all related physical disorders, but because of a lack of analysis due to this disease, PWS do not recognize their condition or make the right decisions to solve problems independently [4]. Difficult relationships with professional caregivers (fear of mental illness, lack of training) and the health system in general (difficulties in access to private practices, environment, cost, etc.) are additional obstacles that contribute to deficient physical care [5].

One of the most visible elements of poor oral health in PWS is a large number of missing or decayed teeth (leading to pain, infection, masticatory and digestive problems) [6]. Dental caries and periodontal or infectious diseases and metabolic disturbances (diabetes, obesity, xerostomia) induced by antipsychotic treatments, poor diet and lifestyle behaviours (diet rich in sugars, use of psychoactive substances such as tobacco, and inadequate oral hygiene) all combine to lead to poor health $[7,8]$.

Generally, negative symptoms, age, duration of mental illness, and low socioeconomic and cultural status are risk factors common to tooth decay [8-10]. These factors are aggravated by stigmatization and discrimination, which is why PWS receive less attention than others in terms of their physical health [11]. Poor oral health can also affect quality of life through the social and psychological impact of the deterioration in smile aesthetics on self-esteem and self-confidence [12]. In France, medical and dental care costs are partly covered for conservative and surgical dental care (70\%), prosthetics and orthodontics treatment (30 to 50\%) by national health insurance and complementary health insurance or by PUMa (Protection Universelle Maladie) or by CMUc (Couverture Médicale Universelle Complémentaire) for people with a low income level (below $8723 €$ per year in 2017). The PUMa and CMUc are free [13].

International data confirm that oral health is poor in people with psychiatric disorders. Dental caries and periodontal measurement indexes are often twice the level found in the general population [8-10]. These results, however, must be clarified. Indeed, in many studies $[3,14]$, schizophrenic populations are rarely differentiated from other populations (bipolar 
disease, major depression) even though they present with distinctive clinical features. The perception of Oral Health related Quality of Life (OHrQoL) was found to be dependent on the particular psychiatric diagnosis [14]. Additionally, most studies have been conducted with in-patients (most marked by the disease) even though most psychiatric patients today live in the community and are managed in psychiatric outpatient units [3].

This population is at greater risk of dental disease, and data on this health problem need to be collected in France. Knowledge of the determinants of oral health in PWS is important to assess preventive oral health needs in this population.

The aim of this study was to assess demographic (age, sex), socioeconomic (education, residential area), lifestyle (tooth brushing frequency, dentist visit frequency and smoking habits), medical condition (number of antipsychotic treatments, illness duration, body mass index, diabetes) and dental condition (oral hygiene, dental caries, xerostomia, and OHrQoL) predictors of oral health of a sample of PWS.

\section{METHODS}

\section{Design}

A multicentre cross-sectional descriptive study was performed between March 2014 and January 2016 in a sample population of PWS recruited from out- and in-patient populations of the three psychiatric hospitals of the Côte d'Or region (Bourgogne). It has 530,000 inhabitants and three hospitals monitoring PWS [15]. The Chartreuse hospital manages persons from rural and urban areas, the Robert Morlevat hospital (Semur-en-Auxois) manages persons from rural areas and Dijon University Hospital manages persons from urban areas. These three hospitals in Côte d'Or include physical and dental consultation and care.

\section{Sample strategy and sample size calculation}

From a population of 1,868 PWS in Côte d'Or recorded in the French medico-administrative database PMSI (Programme de Médicalisation des Système d'Information) of the three hospitals of Cote d'Or, PWS were selected using a random stratified method according to age, sex and hospital, with a probability proportional to the total number of persons in each stratum. Assuming an average standard deviation of 8 [14] and a precision of 1.5, 112 subjects were required. Assuming that $20 \%$ of subjects could not be reached and a response rate of 50\%, 300 subjects were required. Eligible patients were informed by letter and contacted by phone within 2 weeks for out-patients and by the medical staff for in-patients. 
Patients were included if they were over 18 years of age with a diagnosis of schizophrenia (Diagnosis: F20-F29 PMSI) according to the International Classification of Diseases $10^{\text {th }}$ Revision: ICD-10 [16] and were psychically stable. The following patients were excluded: pregnant or breast-feeding women, persons not stabilized from a psychiatric viewpoint, persons experiencing an acute psychiatric episode, persons who could not understand or had poor understanding of French. We also excluded persons who had not updated their social rights to cover the cost of medical and dental care. All the procedures were part of standard care as patients had regular oral and physical examinations.

\section{Study procedure}

\section{Oral examinations / Dental condition}

A single investigator, a dentist, interviewed and clinically examined all the participants using portable dental equipment in the hospital nearest to their place of residence. Pre-packaged and disposable instruments were used. Rating was calibrated in comparison with repeated examinations of a separate pilot sample. Kappa scores of 0.9 for inter-rater agreement were achieved.

Caries experience was assessed using the dentinal (D3) level and the Decayed, Missing, or Filled Teeth (DMFT) index based on 32 teeth and was calculated using WHO (World Health Organization) criteria [17]. Dental plaque and calculi were evaluated on six teeth using the Simplified Oral Hygiene Index (OHI-S). The OHI-S is the sum of the plaque index and the calculus index. The mean OHI-S was computed, and the scores were classified into four levels: Excellent (0); Good (0.1-1.2); Fair (1.3-3.0); Poor (3.1-6.0) [18].

\section{Oral Health Assessment}

Each participant was asked to complete the 'General Oral Health Assessment Index' (GOHAI) [19] and the 'Xerostomia Inventory' (XI) [20] questionnaires and answer other questions related to their socio-economic status (SES) (age, sex, level of education, residential area) and data relating to oral health (tooth brushing frequency, last dental visit).

\section{The Geriatric Oral Health Assessment Index (GOHAI)}

The GOHAI is a self-assessment oral health index. A French version has been validated with PWS [21]. The questionnaire consists of 12 questions that are phrased positively or negatively. The answer modalities are based on a Likert scale with scores ranging from 1 to 5. The GOHAI score is the sum of the answers to the 12 questions. According to Atchison and Dolan, a score of 57 to 60 is regarded as high and corresponds to a satisfactory oral 
health quality of life. A score from 51 to 56 is regarded as average, and a score of 50 or less is regarded as a low score, reflecting a poor oral health quality of life [19].

\section{The Xerostomia Inventory (XI)}

The Xerostomia Inventory (XI) is a self-assessment questionnaire. It is an 11-item summated rating scale that combines the responses to 11 individual items into a single continuous scale score, which represents the severity of chronic xerostomia; higher scores represent more severe symptoms. Respondents are asked to choose one of five responses ('Never', scoring 1; 'Hardly ever', 2; 'Occasionally', 3; 'Fairly often', 4; and 'Very often', 5). Each individual's responses are scored and summed to give a single XI score [20].

\section{General health-related information}

Demographic and medical variables were extracted from institutional medical records: age, sex, presence of diabetes, prescribed drugs at the time of the examination, duration of mental illness (DMI) [22] and Body Mass Index (BMI) [23]. The BMI was stratified into four groups: underweight $(\mathrm{BMI}<18.5)$, normal weight $(\mathrm{BMI}=18.5-25.0)$, overweight $(\mathrm{BMI}=25.0-$ 30.0), and obese (BMI>30.0) based on cut-offs for the European population [23]. Additional variables, namely, the level of education, residential area, smoking habits, tooth brushing frequency, and last dental visit, were collected directly by questioning the patient. Psychiatric status was determined by a clinical assessment conducted by the treating healthcare team.

\section{Data analysis}

Categorical variables were presented as percentages and continuous variables as the means with standard deviations (SD). Associations between the DMFT index or its components (dependent variables) and socio-demographic, lifestyle, clinical, treatment and oral health assessments were first analysed using analysis of variance and Pearson's correlation tests.

Dental caries is an irreversible condition. Assessment of dental status by DMFT index to evaluate the state of oral health based on the presence of decayed teeth (D) which is expressed in a need for care and missing teeth (M) which justifies prosthetic rehabilitating. The presence of filled teeth $(F)$ reflected the state of care. Tooth decay is directly dependent on dental hygiene (OHI-S). Poor oral health can may also affect the quality of life, OHrQOL and oral health is inseparable from general health [24].

A multiple linear regression model was used in subjects who had completed both the OHI-S to find correlates of the DMFT score. A stepwise procedure was used to optimize the model's 
fit. Variables which reached a significance level of $\mathrm{p}<0.2$ in the univariate analysis were included as independent variables and excluded from the final model during the backward elimination process, according to the amount of variance explained. The final model incorporated the standardized $\beta$ coefficients, which represent a change in the standard deviation of the dependent variable (DMFT score) resulting from a change of one standard deviation in the various independent variables. Age, sex and centre were systematically forced into the multivariable model. Collinearity was investigated using collinearity diagnostic procedures. The statistical significance level was set at $\mathrm{p}<0.05$ for a two-sided test. All statistical analyses were performed using SAS statistical software (version 9.1, SAS Institute, Cary, N.C.).

\section{Ethics}

This study was approved by the Committee for the Protection of Persons (CPP) I of Eastern France (registration number: 2014-A00358-39). After providing participants with a complete description of the study, written informed consent was obtained from each participant (or from their legal guardians for persons under guardianship).The study was registered on www.ClinicalTrials.gov under number NCT02167724.

\section{RESULTS}

\section{Study sample}

A study population of 302 persons was selected from the administrative databases. Of the randomized subjects, $22 \%(n=67)$ could not be reached (14 had died, 52 had moved but were still registered at their previous address, one did not have schizophrenia). Among those contacted ( $n=235), 113$ refused to participate in the study, and 13 were unable to cooperate (Figure 1). The acceptance rate was thus $46.4 \%$ ( $n=109$ subjects). Table 1 shows the sociodemographic, lifestyle, clinical, treatment and oral health assessments of the sample.

\section{Demographics}

Among the 109 examined, 61.5\% were men and 38.5\% were women. Age ranged from 25 to 75 years (mean age $46.8 \pm 12.0$ ). The mean age of the non included patients was $48.0 \pm 14.3$ $(n=193)$. In this group $35.8 \%$ were women and $64.2 \%$ were men. No significant differences were found between the two groups in terms of age $(p=0.40)$ and sex $(p=0.619)$. The proportions of the sample by sex, age and centre reflected the proportions of the overall study population by sex, age and centre. 


\section{Medical condition}

The mean number of antipsychotic treatments was $1.92 \pm 1.0$ and that for other treatments was 2.3 \pm 2.2 . The mean DMI was 17.9 years \pm 9.4 and was between (5-19 years) for 54 $(50.5 \%)$ patients. Thirty-two $(29.6 \%)$ had a BMI>30, $20.9 \%$ of men and $43.9 \%$ of women, and 12 patients had non-insulin-dependent diabetes (11.3\%).

\section{Dental condition}

The DMFT was $16.6 \pm 8.1$ with a mean of $2.0 \pm 2.8$ decayed teeth, a mean of 7.7 missing teeth \pm 9.2 and a mean of $6.9 \pm 5.5$ filled teeth (Table 2 indicates tooth decay index by age). Thirteen patients were totally edentate (11.9\%), eleven (84.6\%) had full dentures but only five $(38.5 \%)$ of these patients reported being satisfied with their dentures. Among the 96 dentate patients, the OHI-S index was excellent for only $0.9 \%$, good for $21.1 \%$, fair for $44 \%$ and poor for $22 \%$. The mean GOHAI was $42.2 \pm 7.7$ with poor oral health quality of life for $91 \%$ of the sample, and the mean Xerostomia Inventory score was 22.8 \pm 7.9 .

\section{Factors associated with DMFT score}

The results of the univariate and multivariate analyses are presented in Tables 3, 4 .

In the univariate analysis, the DMFT score was positively associated to age (Pearson $\rho=0.5, p<0.0001)$, XI score $(\rho=0.4, p<0.0001)$ and OHI-S score $(\rho=0.4, p=0.002)$. It was negatively associated to the GOHAI score $(\rho=-0.4, \mathrm{p}<0.0001)$. The mean DMFT score was significantly higher in subjects with a low level of school education, polypharmacy, DMI $\geq$ 20 years and infrequent tooth brushing than in subjects without any of these characteristics. There was no significant association between the mean DMFT score and gender, residence, last dental visit, smoking, BMI and diabetic status.

As the XI score correlated with the GOHAI score $(\rho=-0.7, p<0.0001)$ and as $32 \%$ of XI scores were missing, we decided to exclude the XI score from the multivariate analyses. In subjects who had completed the OHI-S, a low DMFT score remained associated with age $(\beta=0.256, \mathrm{p}<0.001)$, the OHI-S score $(\beta=1.786, \mathrm{p}=0.002)$ and the GOHAI score $(\beta=-0.225$, $\mathrm{p}=0.021$ ), but not with education, tooth brushing habits, polypharmacy and DMI (Table 4).

\section{DISCUSSION}

The study highlights that OHrQOL of PWS was low (mean GOHAI was $42.2 \pm 7.7$ ). The dental and hygiene index score was poor and we observed a lack of brushing and of dental 
visit in this population.

\section{Dental condition}

There are very few data available in the literature on the general population in France, and available data are old (1997-1999). DMFT in 35-44-year-olds was 14.5, and these patients had an average of 1.2 decayed teeth. The number of missing teeth was 3.0, and the number of filled teeth was 10.4 [25]. In comparison, DMFT in 35-44-year-olds in our study was similar (14.1 vs 14.5), whereas the average number of decayed (2.5 vs 1.2) and missing teeth (4 vs 3 ) was higher, and the average number of filled teeth was lower (10.4 vs 7.5). Significantly more PWS had general extractions than did the general population (96\% vs. 80\%) [10]. The number of filled teeth may be a reflection of the treatments available to patients. In our population, although free dental treatment is available, there was a difference between the number of filled teeth in the general population in France and the number in PWS in Côte d'Or. Actually, the difference between PWS and the general French population might be even greater. Available data regarding oral health in the French population are old (1997 and 1999) [25]. As in many industrialized countries, oral health in the French population might have improved over time.

Compared to the literature on PWS (Table 5), mean DMFT $(16.6 \pm 8.1)$ of the study group with mean age $46.8 \pm 12.0$ was lower than that in developing middle-income countries as classified by the World Bank [26] such as Malaysia (20.5 \pm 9.9$)$ with a mean age of $54.8 \pm 16.0$ [12] or Iran (19.4 \pm 7.7$)$ with a mean age of 38.8 \pm 10.4 [27] for hospitalized patients. Compared to high-income countries such as France, we observed that DMFT in Spain was

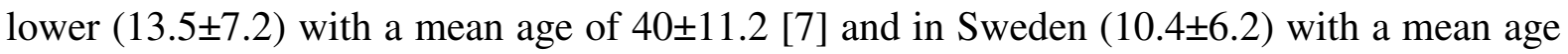
between 20 and 65 years old for outpatients [28]. In the present study, DMFT in France was lower compared to hospitalized patients in Japan (18.8 \pm 7.0$)$ with a mean age of $55.6 \pm 13.4$ [29] and Greece (23.3 \pm 8.3$)$ with a mean age of $50.3 \pm 13.0$ [8]. In the study by BertaudGounot et al. [14] the DMFT was $15.8 \pm 8.8$ with a mean age of $46.9 \pm 17.5$ in France (Rennes) in a sample of 165 psychiatric in-patients (59 schizophrenic persons in the sample). In this psychiatric hospital, the somatic care ward includes dental care or dental consultations.

In France, some psychiatric hospitals only have a somatic care ward that includes dental care or dental consultations. In this country, the somatic care of patients undergoing psychiatric treatment remains heterogeneous, and care management modes differ from one department to another, and data are not available. 


\section{Socio-economic status}

In accordance with a previous study [14], we showed that age over 45 years, length of hospitalization over 5 years, disability and plaque index over 1 were significant contributors to having a high DMFT (over 16). In other studies, among the subjects with schizophrenia, DMFT was significantly related to independent variables such as age, education, and grade of disability [30].

To our knowledge, this is the first time the OHrQOL has been explored in PWS using the GOHAI scale. In the present study PWS clearly express their poor OHrQOL in accordance with poor oral health. Whereas some paradoxical situations were described where patients with serious and persistent disabilities report that they experience a good or excellent quality of life [31]. In older adults, high GOHAI scores were found not in accordance with the severity of the impact of oral diseases [32]. In this situation, the objective dental status is disconnected from the subjective perception of oral health and quality of life.

Given the impact of oral health on overall health and quality of life, the impact of self-perceived oral health in PWS should be explored in the future with qualitative studies to better understand the oral health and dental care needs in this population [33].

\section{Medical condition}

Schizophrenic patients generally have life-long treatment for the symptoms of the disease and take more than two drugs daily to address the symptoms of schizophrenia [34].

Concerning medical conditions, our study showed that $29.6 \%$ of the patients had a BMI $>30$. Generally, in a psychiatric population, $31 \%$ of men and $37 \%$ of women have a $\mathrm{BMI}>30[35]$.

PWS have a higher rate of diabetes mellitus than the general population. It seems that the frequency of diabetes mellitus is higher in older schizophrenic patients [36]. Many factors can contribute to glycaemic disturbances, such as negative symptoms, which increase with time, unbalanced diets, toxic habits and the consumption of antipsychotics [33]. But in our study we don't observed this relation $(\mathrm{p}=0.0555)$ probably in relation with the small size of your population. Diabetes is a risk factor likely to contribute to the development of periodontal disease. The control of periodontal infection could furthermore contribute to the control of diabetes. Periodontal disease could may also be a risk factor for cardiovascular diseases (ischemic heart disease), and could be associated with a high rate of mortality in PWS [37]. 


\section{Lifestyle}

In their study, Mallet et al. [38] observed that 53.7\% of PWS were smokers in France which is higher that observed in the general population (34.1\%) [39]. Patients with tobacco use present clinical specificities that may involve different physiological pathways, involving at least interactions between cholinergic-nicotinic system and dopaminergic system. In our study, we observed more missing teeth in PWS smoking population. Therefore, understanding smoking patterns in major psychiatric disorders is important to develop effective interventions for smoking cessation and reduction of harmful outcomes.

A lack of brushing and of dental visit is observed in our population. It should also be noted that PWS visit dentists much less frequently than the general population $[40,41]$.

\section{Strengths and limitations}

To our knowledge, this is the first study to consider in- and out-patients with schizophrenia in France. However, regardless the sampling procedure used to obtain samples, cohorts are ultimately composed of volunteers who may differ from the target population and our results in Côte d'Or region cannot be generalized to all of France. This also highlighted the difficulties to include PWS in research protocols. Secondly, some limitations in the use of the PMSI database to identify PWS can be pointed out. Diagnostic codes F20-F29 of PMSI data bases are not accurate enough. Indeed they take into account heterogeneous schizophrenia symptoms and can induce an under-estimation of the schizophrenia population. Conversely, considering that schizophrenic symptoms might not be subsequently confirmed (transient schizophrenic disorder) could induce a risk of over-estimation. In order to be more exhaustive, we should take in account chronic disease status, drugs and hospitalisations conditions (mean duration, number of hospitalizations...) The REDSIAM (Réseau données Sniiram) network suggested different combinations of selected criteria in order to identify adult schizophrenia in the SNIIRAM (Système national d'information inter-regimes de l'assurance maladie) data base [42]. Our study could introduce a national survey with the REDSIAM network. Thirdly, in this study, indicators for oral function (deficiencies in chewing, swallowing, speaking) were not considered even though they are important oral problems. Alcohol and drug consummation habits were not assessed either and could be explored in further studies. 


\section{CONCLUSIONS}

This study highlighted that PWS describe a poor OHrQoL. We observed a poor dental and hygiene index score. PWS visited a dentist less frequently, and they brushed their teeth less often. Finally, our findings illustrated a gap in oral health between PWS and general population in France.

In practice, to improve this major public health issue in France, since 2016, a dental check-up is recommended for all new admissions to a psychiatric hospital.

We are awaiting the results of a cluster randomized controlled trial to assess the effectiveness of a therapeutic educational programme in oral health for PWS (www.ClinicalTrials.gov under number NCT02167724) [43] funded by the French Ministry of Health. This therapeutic educational programme is potentially a new care support strategy for improving the OHrQoL of PWS.

\section{REFERENCES}

[1] Jablensky A. Epidemiology of schizophrenia: the global burden of disease and disability. Eur Arch Psychiatry Clin Neurosci. 2000;250(6):274-285.

[2] Wildgust HJ, Hodgson R, Beary M. The paradox of premature mortality in schizophrenia: new research questions. J Psychopharmacol. 2010;24(4):9-15.

[3] Kisely S, Baghaie H, Lalloo R, et al. A systematic review and meta-analysis of the association between poor oral health and severe mental illness. Psychosom Med. 2015;77(1):83-92.

[4] Grisso T, Appelbaum PS. Comparison of standards for assessing patients' capacities to make treatment decisions. Am J Psychiatry. 1995;152(7):1033-1037.

[5] Kisely S, Smith M, Lawrence D, et al. Inequitable access for mentally ill patients to some medically necessary procedures. Can Med Assoc J. 2007;176(6):779-784.

[6] Rai B. Systemic effect of oral disease. Internet J Fam Pract. 2006;5(1):1-3.

[7] Arnaiz A, Zumarraga M, Diez-Altuna I, et al. Oral health and the symptoms of schizophrenia. Psychiatry Res. 2011;188(1):24-28.

[8] Thomas A, Lavrentzou E, Karouzos C, et al. Factors which influence the oral condition of chronic schizophrenia patients. Spec Care Dent. 1996;16(2):84-86. 
[9] Gurbuz O, Alatas G, Kurt E, et al. Oral health and treatment needs of institutionalized chronic psychiatric patients in Istanbul, Turkey. Community Dent Health. 2010;27(3):151-157.

[10] McCreadie RG, Stevens H, Henderson J, et al. The dental health of people with schizophrenia. Acta Psychiatr Scand. 2004;110(4):306-310.

[11] Moore S, Shiers D, Daly B, et al. Promoting physical health for people with schizophrenia by reducing disparities in medical and dental care. Acta Psychiatr Scand. 2015;132(2):109-121.

[12] Wey MC, Loh S, Doss JG, et al. The oral health of people with chronic schizophrenia: a neglected public health burden. Aust N Z J Psychiatry. 2016;50(7):685-694.

[13] La-mise-en-place-de-la-Protection-Universelle-Maladie-PUMA-au-1er-janvier-2016 [Internet].France: Le portail du service public de la Sécurité social;[cited 2017 Apr 23].Available from: http://www.securite-sociale.fr/

[14] Bertaud-Gounot V, Kovess-Masfety V, Perrus C, et al. Oral health status and treatment needs among psychiatric inpatients in Rennes, France: a cross-sectional study. BMC Psychiatry. 2013;13:227.

[15] Institut National de la Statistique Économique [Internet]. France: La Côte d'Or 21 en bref pdf 2010; [cited 2016 Dec 30]. Available from: https://www.insee.fr/fr/statistiques/1288793

[16] International Statistical Classification of Diseases and Related Health Problems. 10th Revision [Internet]. Geneva: Word Health Organization; 2010. [cited 2016 Dec 30]. Available from: http://apps.who.int/classifications/apps/icd/icd10online/

[17] World Health Organization. Oral health surveys: basic methods. Geneva: World Health Organization; 2013.

[18] Greene JC, Vermillion JR. The simplified oral hygiene index. J Am Dent Assoc. $1964 ; 68: 7-13$.

[19] Atchison KA, Dolan TA. Development of the geriatric oral health assessment index. J Dent Educ. 1990;54(11):680-687.

[20] Thomson WM, van der Putten GJ, de Baat C, et al. Shortening the xerostomia inventory. Oral Surg Oral Med Oral Pathol Oral Radiol Endod. 2011;112(3):322-327.

[21] Denis F, Hamad M, Trojak B, et al. Psychometric characteristics of the "General Oral Health Assessment Index (GOHAI)" in a French representative sample of patients with schizophrenia. BMC Oral Health. 2017;17(1):75. 
[22] Lesh TA, Niendam TA, Minzenberg MJ, et al. Cognitive control deficits in schizophrenia: mechanisms and meaning. Neuropsychopharmacology. 2011;36(1):316-338.

[23] World Health Organization. Waist Circumference and Waist-Hip Ratio: Report of a WHO Expert Consultation [Internet]. Geneva, Switzerland: World Health Organization; 2008. [cited 2016 Dec 30]. Available from: http://apps.who.int/iris/bitstream/10665/44583/1/9789241501491_eng.pdf

[24] Moore S, Shiers D, Daly B, Mitchell AJ, Gaughran F. Promoting physical health for people with schizophrenia by reducing disparities in medical and dental care. Acta Psychiatr Scand. 2015;132:109-21.

[25] Hescot P, Bourgeois D, Doury J. Oral health in 35-44 year old adults in France. Int Dent J. 1997;47(2):94-99.

[26] World Bank. Country and Lending Groups 2016 [Internet]. Washington (DC): [cited 2017 Apr 25]. Available from: http://data.worldbank.org/about/country-and-lendinggroups\#Upper_middle_income

[27] Nikfarjam M, Parvin N. Oral health status in three long term care units of schizophrenic patients in Chaharmahal-Bakhtiari province, Iran. Iran Red Crescent Med J. 2013;15(4):371-372.

[28] Persson K, Axtelius B, Soderfeldt B, et al. Monitoring oral health and dental attendance in an outpatient psychiatric population. J Psychiatr Ment Health Nurs 2009;16(3):263-271.

[29] Tani H, Uchida H, Suzuki T, et al. Dental conditions in inpatients with schizophrenia: a large-scale multi-site survey. BMC Oral Health. 2012;12:32.

[30] Chu KY, Yang NP, Chou P, et al. The relationship between body mass index, the use of second-generation antipsychotics, and dental caries among hospitalized patients with schizophrenia. Int J Psychiatry Med. 2011;41(4):343-353.

[31] Albrecht GL, Devlieger PJ. The disability paradox: high quality of life against all odds. Soc Sci Med 1999;48:977-988.

[32] Wallace J, Pfohl B. Age-related differences in the symptomatic expression of major depression. J Nerv Ment Dis 1995;183:99-102.

[33] Tang LR, Zheng W, Zhu H, et al. Self-reported and interviewer-rated oral health in patients with schizophrenia, bipolar disorder, and major depressive disorder. Perspect Psychiatr Care. 2016;52(1):4-11. 
[34] Parsons B, Allison DB, Loebel A, et al. Weight effects associated with antipsychotics: a comprehensive database analysis. Schizophr Res. 2009;110(1-3):103-110.

[35] Allison DB, Casey DE. Antipsychotic-induced weight gain: a review of the literature. J Clin Psychiatry. 2001;62:22-31.

[36] Eltas A, Kartalci S, Eltas SD, et al. An assessment of periodontal health in patients with schizophrenia and taking antipsychotic medication. Int $\mathrm{J}$ Dent Hyg. 2013;11(2):78-83.

[37] Desvarieux M, Demmer RT, Rundek T, Boden-Albala B, Jacobs DR, Papapanou PN, et al. Relationship between periodontal disease, tooth loss, and carotid artery plaque: the Oral Infections and Vascular Disease Epidemiology Study (INVEST). Stroke. 2003;34:2120-5.

[38] Mallet J, Le Strat Y, Schürhoff F et al. Cigarette smoking and schizophrenia: a specific clinical and therapeutic profile? Results from the FACE-Schizophrenia cohort.

Prog Neuropsychopharmacol Biol Psychiatry. 2017;3(79):332-339.

[39] Guignard, R., Beck, F., Wilquin, J.L et al. La consommation de tabac en France et son évolution: résultats du Baromètre santé 2014. Bull. Epidémiologique Hebd. 2015 ; 281-288

[40] Nielsen J, Munk-Jorgensen P, Skadhede S, et al. Determinants of poor dental care in patients with schizophrenia: a historical, prospective database study. J Clin Psychiatry. 2011;72(2):140-143.

[41] Sayegh F, Dababneh R, Rodan R. Oral health status and dental treatment needs among non-institutionalized psychiatric patients. JRMS. 2006;13(1):27-31.

[42] Quantin C et al.[Study of algorithms to identify schizophrenia in the SNIIRAM database conducted by the REDSIAM network]. Rev Epidemiol Sante Publique. 2017;65 Suppl 4:S226-S235.

[43] Denis F, Millot I, Abello N, et al. Study protocol: a cluster randomized controlled trial to assess the effectiveness of a therapeutic educational program in oral health for persons with schizophrenia. Int J Ment Health Syst. 2016;10:65. 
List of out- or in-patients schizophrenic persons from the administrative databasee of the psychiatric hospitals of Côte d'Or $\mathrm{n}=1868$

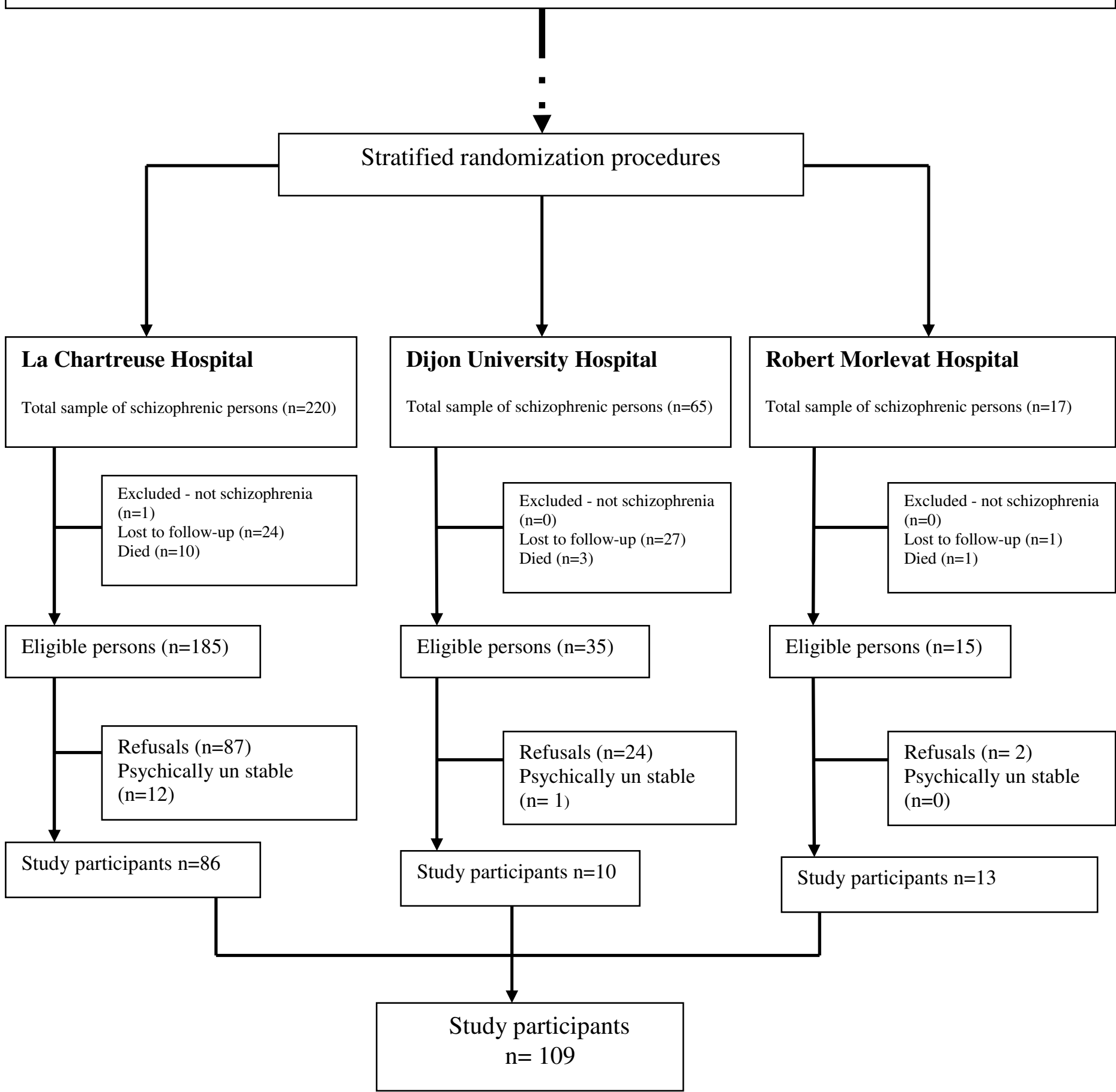

Figure 1. Patient recruitment flow chart 
Table 1. Characteristics of sample studied $(n=109)$

$\begin{array}{lrr}\text { Demographic } & & \\ \text { Age (years) m (sd) } & & \\ 46.8(12.0) & & \\ \text { Age groups n (\%) } & & \\ 25-34 & 19 & 17.5 \% \\ 35-44 & 32 & 29.4 \% \\ 45-54 & 25 & 22.9 \% \\ 55-64 & 24 & 22.0 \% \\ \geq 65 & 9 & 8.2 \%\end{array}$

Sex n $(\%)$

Female

Male

Socio-economic status

Education $\mathrm{n}(\%)$

Primary school or less

Secondary or higher

Residence $\mathrm{n}(\%)$

Out-patient

In-patient

Lifestyle

Brushing habits $\mathrm{n}(\%)$

Never to occasionally

Every day

Other

Last dental visit $\mathrm{n}(\%)$

$<6$ months

$\geq 6$ months

Smoking n (\%)

Yes

No

Cigarettes per day

[range, $\mathrm{m}, \mathrm{Sd}$ ]

Medical condition

Treatment $\mathrm{n}(\%)$

$\begin{array}{lll}<4 & 60 & 55.5 \% \\ \geq 4 & 48 & 44.4 \%\end{array}$

Illness duration $\mathrm{n}(\%)$

$\begin{array}{lrr}1-4 & 4 & 3.7 \% \\ 5-19 & 54 & 50.5 \% \\ \geq 20 & 49 & 45.8 \%\end{array}$

BMI n (\%)

Underweight $<18.5 \quad 2 \quad 1.8 \%$

Normal [15.5-25] $\quad 38 \quad 35.2 \%$

Overweight [25-30] $36 \quad 33.3 \%$

$\begin{array}{lll}\text { Obese }>30 & 32 & 29.6 \%\end{array}$

Diabetic n (\%)

Yes $\quad 12 \quad 11.3 \%$

$\begin{array}{lll}\text { No } & 94 & 88.7 \%\end{array}$

Dental condition

OHI-S n (\%)

Excellent $\quad 1 \quad 0.9 \%$

Good $\quad 23 \quad 21.1 \%$

Fair $\quad 48 \quad 44.0 \%$

$\begin{array}{lll}\text { Poor } & 24 & 22.0 \%\end{array}$

No teeth $\quad 13 \quad 11.9 \%$

OHI-S m(sd)

$2.2(1.2)$

DMFT m(sd)

$16.6(8.1)$

Decayed $\mathrm{m}(\mathrm{sd})$

$2.0(2.8)$

Missing $\mathrm{m}(\mathrm{sd})$

$7.6(9.2)$

Filled $\mathrm{m}(\mathrm{sd})$

$6.9(5.4)$

GOHAI m(sd)

42.2 (7.7)

GOHAI score $\mathrm{n}(\%)$

$\begin{array}{lll}\text { High [57-60] } & 1 & 0.9 \%\end{array}$

$\begin{array}{lll}\text { Average [51-56] } & 8 & 7.9 \%\end{array}$

$\begin{array}{lll}\text { Low } \leq 50 & 92 \quad 91.0 \%\end{array}$

XI m(sd)

$22.8(7.9)$

Sd: standard deviation; BMI: Body Mass Index; DMFT: decayed-missing-filled teeth; OHI-S: Debris Index of the Simplified Oral Hygiene Index; GOHAI: Geriatric Oral Health Assessment Index; XI: Xerostomia Inventory. ${ }^{*} \mathrm{p}<0.05 * * \mathrm{p}<0.01 * * * \mathrm{p}<0.001$ 
Table 2. Tooth decay index (DMFT scores) by age

\begin{tabular}{|c|c|c|c|c|}
\hline & Decayed $\mathrm{m}(\mathrm{sd})$ & Missing $\mathrm{m}(\mathrm{sd}) * * *$ & Filled $\mathrm{m}(\mathrm{sd})^{*}$ & DMFT m(sd)*** \\
\hline \multicolumn{5}{|l|}{ Age (years) } \\
\hline $25-34$ & $2.0(2.6)$ & $3.4(7.3)$ & $4.6(4.2)$ & $10.0(8.4)$ \\
\hline $35-44$ & $2.5(3.6)$ & $4.0(5.3)$ & $7.5(4.5)$ & $14.1(6.4)$ \\
\hline $45-54$ & $2.3(2.9)$ & $7.3(7.4)$ & $8.8(5.5)$ & $18.4(7.3)$ \\
\hline $55-64$ & $1.6(1.9)$ & $13.0(10.4)$ & $6.9(6.2)$ & $21.5(5.8)$ \\
\hline$\geq 65$ & $0.8(1.5)$ & $16.4(13.0)$ & $4.4(7.0)$ & $21.7(9.3)$ \\
\hline
\end{tabular}

Legend: Sd: standard deviation; DMFT: decayed-missing-filled teeth. $* \mathrm{p}<0.05 * * \mathrm{p}<0.01$ $* * * \mathrm{p}<0.001$ 
Table 3. Dental status (DMFT scores) by demographic, socioeconomic, medical, dental and behavioural characteristics of the sample.

\begin{tabular}{|c|c|c|c|c|c|}
\hline & $\mathbf{n}$ & $\begin{array}{c}\text { Decayed } \\
\text { m(sd) }\end{array}$ & $\begin{array}{c}\text { Missing } \\
\text { m(sd) }\end{array}$ & $\begin{array}{l}\text { Filled } \\
\text { m(sd) }\end{array}$ & $\begin{array}{c}\text { DMFT } \\
\text { m(sd) }\end{array}$ \\
\hline \multicolumn{6}{|l|}{ Sex } \\
\hline Female & 42 & $1.9(3.2)$ & $7.0(9.1)$ & $7.8(5.6)$ & $16.8(7.4)$ \\
\hline Male & 67 & $2.1(2.5)$ & $8.1(9.3)$ & $6.3(5.3)$ & $16.5(8.6)$ \\
\hline \multicolumn{6}{|l|}{ Education } \\
\hline Primary school or less & 24 & $2.1(3.3)$ & $11.3(10.3)^{*}$ & $7.0(6.6)$ & $20.5(6.9)^{* *}$ \\
\hline Secondary or higher & 85 & $2.0(2.8)$ & $6.6(8.6)$ & $6.9(5.1)$ & $15.5(8.2)$ \\
\hline \multicolumn{6}{|l|}{ Residence } \\
\hline Out-patient & 87 & $1.8(2.5)$ & $7.2(8.8)$ & $7.3(5.4)$ & $16.2(7.9)$ \\
\hline In-patient & 22 & $3.2(3.9)$ & $9.7(10.7)$ & $5.5(5.7)$ & $18.4(9.1)$ \\
\hline \multicolumn{6}{|l|}{ Tooth brushing habits } \\
\hline Never to Occasionally & 29 & $3.2(3.6)^{*}$ & $9.1(8.8)$ & $6.3(5.6)$ & $18.7(7.7)^{*}$ \\
\hline Every day & 69 & $1.5(2.4)$ & $6.1(8.5)$ & $7.5(5.4)$ & $15.1(7.8)$ \\
\hline \multicolumn{6}{|l|}{ Last dental visit } \\
\hline$<6$ months & 57 & $2.2(3.0)$ & $8.5(9.8)$ & $5.3(5.1)^{* *}$ & $16.1(8.9)$ \\
\hline$\geq 6$ months & 50 & $1.7(2.4)$ & $6.4(8.0)$ & $8.8(5.3)$ & $17.0(7.3)$ \\
\hline \multicolumn{6}{|l|}{ Smoking } \\
\hline No & 48 & $1.5(2.1)$ & $5.6(7.7)^{*}$ & $8.2(5.5)^{*}$ & $15.4(7.9)$ \\
\hline Yes & 60 & $2.4(3.2$ & $9.4(10)$ & $5.8(5.2)$ & $17.7(8.3)$ \\
\hline \multicolumn{6}{|c|}{ Treatment ( $n^{\circ}$ of drugs) } \\
\hline$<4$ & 48 & $1.6(2.6)$ & $5.4(8.0) *$ & $7.1(5.6)$ & $14.2(8.2)^{* *}$ \\
\hline$\geq 4$ & 60 & $2.3(2.9)$ & $9.6(9.7)$ & $6.7(5.4)$ & $18.7(7.7)$ \\
\hline \multicolumn{6}{|l|}{ Duration of illness } \\
\hline$<20$ years & 58 & $1.8(2.4)$ & $5.6(8.5)^{*}$ & $6.7(5.4)$ & $14.3(8.3)^{* *}$ \\
\hline$\geq 20$ years & 49 & $2.3(3.2)$ & $9.7(9.3)$ & $7.2(5.6)$ & $19.3(7.1)$ \\
\hline \multicolumn{6}{|l|}{ BMI } \\
\hline$<30$ & 76 & $2.2(3.0)$ & $8.2(9.5)$ & $6.2(5.1)$ & $16.6(8.0)$ \\
\hline$\geq 30$ & 32 & $1.7(2.4)$ & $6.4(8.6)$ & $8.6(6.0)$ & $16.7(8.6)$ \\
\hline \multicolumn{6}{|l|}{ Diabetic } \\
\hline No & 94 & $2.1(2.8)$ & $7.2(8.8)$ & $7.0(5.4)$ & $16.4(8.0)$ \\
\hline Yes & 12 & $1.4(3.0)$ & $12.6(11.4)$ & $6.0(6.3)$ & $20.0(9.0)$ \\
\hline \multicolumn{6}{|l|}{ OHI-S } \\
\hline$<3$ & 68 & $1.3(1.7)^{*}$ & $3.6(5.2) * *$ & $8.7(5.1)^{* *}$ & $13.8(7.1)^{* *}$ \\
\hline$\geq \mathbf{3}$ & 28 & $4.2(4.0)$ & $8.5(7.3)$ & $5.5(4.6)$ & $18.2(7.6)$ \\
\hline \multicolumn{6}{|l|}{ GOHAI } \\
\hline$<44$ & 48 & $2.5(3.3)$ & $12.1(10.1)^{* * *}$ & $6.0(5.4)$ & $20.7(7.0)^{* * *}$ \\
\hline$\geq 44$ & 53 & $1.7(2.3)$ & $4.2(6.8)$ & $7.6(5.4)$ & $13.7(7.7)$ \\
\hline$<51$ & 92 & $2.2(2.9)$ & $8.0(9.3)$ & $6.8(5.3)$ & $18.5(8.1)^{* *}$ \\
\hline$\geq 51$ & 9 & $1.6(2.7)$ & $8.7(11.1)$ & $8.3(7.3)$ & $16.9(8.2)$ \\
\hline \multicolumn{6}{|l|}{ XI } \\
\hline$<22$ & 37 & $1.4(2.0)$ & $3.5(5.6) * * *$ & $8.1(5.6)$ & $13.1(7.8)^{* *}$ \\
\hline \multirow[t]{3}{*}{$\geq 22$} & 37 & $2.4(3.6)$ & $10.8(10.7)$ & $6.0(5.8)$ & $19.3(8.0)$ \\
\hline & $\mathrm{n}$ & Decayed & Missing & Filled & DMFT \\
\hline & & $\rho$ & $\rho$ & $\rho$ & $\rho$ \\
\hline Age & 109 & -0.1 & P.4*** & -0.01 & $0.5 * * *$ \\
\hline OHI-S & 96 & $0.5^{* *}$ & $0.5 * * *$ & $-0.3 * *$ & $0.4 * *$ \\
\hline GOHAI & 101 & -0.1 & $-0.5^{* * *}$ & $0.3^{* *}$ & $-0.4 * * *$ \\
\hline XI & 74 & 0.05 & $0.5 * * *$ & $-0.2 *$ & $0.4 * * *$ \\
\hline
\end{tabular}

Legend: $\mathrm{m}$ : mean ; Sd : standard deviation; $\rho$ : Pearson correlation ; BMI: Body Mass Index; DMFT: decayed-missing-filled teeth; OHI-S: Debris Index of the Simplified Oral Hygiene Index; GOHAI: Geriatric Oral Health Assessment Index; XI: Xerostomia Inventory. ${ }^{*} \mathrm{p}<0.05$ $* * \mathrm{p}<0.01 \quad * * * \mathrm{p}<0.001$ 
Table 4. Factors associated with DMFT score

(multivariate linear regression model)

\begin{tabular}{lcc}
\hline & $\beta$ & $\mathbf{p}$ \\
\hline AGE & 0.256 & $<.0001$ \\
OHIS score & 1.786 & 0.001 \\
GOHAI score & -0.225 & 0.021 \\
FEMALE & -0.286 & 0.839 \\
MALE & 0.000 & - \\
The Robert Morlevat Hospital & 3.798 & 0.237 \\
The Chartreuse Hospital & 1.970 & 0.438 \\
Dijon University Hospital & 0.000 & - \\
\hline
\end{tabular}

Legend: $\beta$ : beta, OHI-S: Debris Index of the Simplified Oral Hygiene Index; GOHAI:Geriatric Oral Health Assessment Index $\mathrm{p}$ values are estimated after adjustment for gender, age, center, OHIS score and GOHAI score 
Table 5. International comparisons of DMFT scores

\begin{tabular}{|c|c|c|c|c|c|}
\hline Year & Country & $\begin{array}{l}\text { Outpatient or } \\
\text { Hospitalized }\end{array}$ & $\mathrm{n}$ & $\begin{array}{l}\text { Average } \\
\text { age } \mathrm{m}(\mathrm{sd})\end{array}$ & $\begin{array}{l}\text { DMFT } \\
\mathrm{m}(\mathrm{sd})\end{array}$ \\
\hline 2016 & France & $\begin{array}{l}\text { In and } \\
\text { outpatient }\end{array}$ & 109 & $46.8(12.0)$ & $16.6(8.1)$ \\
\hline 2015 & Malaysia [12] & Hospitalized & 543 & $54.8(16.0)$ & $20.5(9.9)$ \\
\hline 2013 & Iran [26] & Hospitalized & 123 & $38.8(10.4)$ & $19.4(7.7)$ \\
\hline 2012 & Japan [28] & Hospitalized & 523 & $55.6(13.4)$ & $18.8(7.0)$ \\
\hline 1996 & Greece [8] & Hospitalized & 249 & $50.3(13.0)$ & $23.3(8.3)$ \\
\hline 2011 & Spain [7] & Outpatient & 66 & $40(11.2 .0)$ & $13.5(7.2)$ \\
\hline 2009 & Sweden [27] & Outpatient & 33 & $\begin{array}{l}\text { Between } 20 \\
\text { and } 65 \\
\text { years old }\end{array}$ & $10.4(6.2)$ \\
\hline
\end{tabular}

